\title{
Anterolateral minithoracotomy versus median sternotomy for mitral valve disease: a meta-analysis
}

\author{
Chao DING ${ }^{1}$, Da-ming JIANG ${ }^{\dagger 2}$, Kai-yu TAO ${ }^{2}$, Qun-jun DUAN ${ }^{2}$, \\ Jie $\mathrm{LI}^{3}$, Min-jian KONG ${ }^{2}$, Zhong-hua SHEN ${ }^{2}$, Ai-qiang $\mathrm{DONG}^{2}$ \\ ( ${ }^{1}$ Department of Gynaecology, Zhejiang Cancer Hospital, Hangzhou 310022, China) \\ ( ${ }^{2}$ Department of Cardiovascular Surgery, the Second Affiliated Hospital, School of Medicine, Zhejiang University, Hangzhou 310009, China) \\ ( ${ }^{3}$ Guangdong Cardiovascular Institute, Guangdong General Hospital, Guangdong Academy of Medical Sciences, Guangzhou 510030, China) \\ 'E-mail: to_jiangdm@163.com \\ Received Aug. 10, 2013; Revision accepted Feb. 10, 2014; Crosschecked May 26, 2014
}

\begin{abstract}
Objective: Mitral valve disease tends to be treated with anterolateral minithoracotomy (ALMT) rather than median sternotomy (MS), as ALMT uses progressively smaller incisions to promote better cosmetic outcomes. This meta-analysis quantifies the effects of ALMT on surgical parameters and post-operative outcomes compared with MS. Methods: One randomized controlled study and four case-control studies, published in English from January 1996 to January 2013, were identified and evaluated. Results: ALMT showed a significantly longer cardiopulmonary bypass time $(P=0.001)$ and aortic cross-clamp time $(P=0.05)$ compared with MS. However, the benefits of ALMT were evident as demonstrated by a shorter length of hospital stay $(P<0.00001)$. According to operative complications, the onset of new arrhythmias following ALMT decreased significantly as compared with MS $(P=0.05)$; however, the incidence of peri-operative mortality $(P=0.62)$, re-operation for bleeding $(P=0.37)$, neurologic events $(P=0.77)$, myocardial infarction $(P=0.84)$, gastrointestinal complications $(P=0.89)$, and renal insufficiency $(P=0.67)$ were similar to these of MS. Long-term follow-up data were also examined, and revealed equivalent survival and freedom from mitral valve events. Conclusions: Current clinical data suggest that ALMT is a safe and effective alternative to the conventional approach and is associated with better short-term outcomes and a trend towards longer survival.
\end{abstract}

Key words: Minimally invasive surgical procedures, Anterolateral minithoracotomy (ALMT), Median sternotomy (MS), Mitral valve, Meta-analysis

doi:10.1631/jzus.B1300210

Document code: A

CLC number: R654.2

\section{Introduction}

Historically, most mitral valve surgery has been performed using conventional full median sternotomy (MS). In the late 1990s, a new procedure termed 'minimally invasive mitral valve surgery' (MIMVS) was being suggested (Cosgrove III et al., 1998; Gundry et al., 1998; Byrne et al., 2000; Gillinov et al., 2000). This procedure can minimize surgical trauma, resulting in reduced operative mortality, less pain, improved quality of life, and better cosmetic results

\footnotetext{
ॠCorresponding author

(c) Zhejiang University and Springer-Verlag Berlin Heidelberg 2014
}

by reducing the size of the incision, particularly for young females and older people (Walther et al., 1999; Soltesz and Cohn, 2007). MIMVS involves partial sternotomy, hemi-sternotomy, anterolateral minithoracotomy (ALMT), and total endoscopic approaches.

MIMVS is not a simple approach, rather a synthesis of new techniques and operation-specific technologies that are technically demanding and time-consuming. Most surgeons have regarded minimally invasive valve procedures as unnecessary and unsafe owing to limited exposure and increased technical difficulty, which may increase the risk of intra-operative myocardial and cerebral problems (Mohr et al., 1998; Vanermen et al., 1999; Glower 
et al., 2001). One recent review even suggested that demonstrable and reproducible benefits of the minimally invasive approach were restricted to cosmetic aspects (Anyanwu and Adams, 2012). Thus, the question remains as to whether the potential benefits of a minimally invasive approach can outweigh the potential drawbacks of limited operative exposure, longer cardiopulmonary bypass time and aortic crossclamp time. One recent meta-analysis of minimal access mitral valve surgery (Modi et al., 2008), which collected data from 1996 to 2008, suggested some short- and long-term benefits for mortality, reoperation for bleeding, intensive care unit (ICU) stay, and hospital stay over conventional surgery, despite longer operative time. However, this meta-analysis included all kinds of minimally invasive approaches without any subgroups or randomized clinical trials.

ALMT is one of the most common minimally invasive approaches. The current preferred minimally invasive approach for the mitral valve is the right ALMT, which can be employed in those requiring concomitant management of tricuspid regurgitation or atrial fibrillation (Gillinov and Mihaljevic, 2012; Sündermann et al., 2012). A new meta-analysis specially focusing on ALMT for the last 17 years (1996-2013) of investigational data is needed. This new meta-analysis aims to provide evidence regarding the effects of ALMT compared with MS for the treatment of mitral valve disease.

For ALMT to be utilized widely, short-term outcomes and long-term results must be characterized and compared with those of MS. Additional evidence is required from large, multi-center prospective randomized controlled trials (RCTs) that compare ALMT with MS. However, it is unlikely that patients would participate in a trial with randomization to sternotomy as a control cohort because of preconceived notions. In the absence of large, well-designed RCTs, alternative data are available from multiple case-control studies.

\section{Materials and methods}

\subsection{Search strategies}

Searches for all relevant published articles were performed in Google Scholar, Medline, PubMed Central, and Embase databases from January 1996 to
January 2013. The eligibility of every study having more than one author during the search was assessed. Search keywords were "minithoracotomy, median sternotomy, mitral". To represent contemporary practice, the search was limited to the last 17 years, and additional limits were English language citations and human subjects. Reference lists of every relevant article were searched.

\subsection{Inclusion and exclusion criteria}

The studies were selected according to the following inclusion criteria: (1) the type of study: RCTs and case-control studies were used for the metaanalysis if they included at least one of the outcomes of interest; (2) participants: patients with mitral valve disease undergoing right ALMT.

The exclusion criteria were: (1) any other type of minimally invasive surgery, such as robotic surgery or endo-aortic balloon occlusion; (2) studies reporting re-operative data; (3) reports in a language other than English; (4) studies without a control group or with a control group that was not MS; (5) studies in which data were not presented as the mean and standard deviation (SD) or were not calculable; (6) studies in which the mitral data were not presented separately from other valve data.

\subsection{Outcome measures}

Only the outcome measures presented in more than two included studies were analyzed in our study. Cardiopulmonary bypass (CPB) time, aortic crossclamp time (ACCT), length of hospital stay (LOHS), peri-operative mortality, and post-operative complications (re-operation for bleeding, neurologic events, gastrointestinal complications, arrhythmias, renal insufficiency, myocardial infarction, and sepsis) were selected for analysis.

\subsection{Statistical analysis}

Review Manager V.5.1 was used for statistical analysis. Meta-analyses were performed using either odds ratios (ORs) or weighted mean differences (WMDs) as the summary statistics for discontinuous or continuous variables, respectively. Statistical significance was set at $P<0.05$. We tested heterogeneity using the $\chi^{2}$ test, $I^{2}$ test, and degrees of freedom. Random effects models were used presuming that outcome measures of each study were variable, and 
surgical data as selection criteria and risk profiles for patients differed among centers. In the present metaanalysis, the risk of bias was not assessed.

\section{Results}

Five published reports were identified: one RCT (Speziale et al., 2011) and four case-control studies (Felger et al., 2001; de Vaumas et al., 2003; Iribarne et al., 2010; Holzhey et al., 2011) (Table 1). Two studies, Chitwood et al. (1997) and Iribarne et al. (2012), were excluded because additional inclusive data were found from the same groups of Felger $e t$ al. (2001) and Iribarne et al. (2010), respectively. In total, we identified 379 studies by searching databases. Excluded studies were either meta-analyses $(n=2)$, studies without the expected procedure $(n=8)$, studies involving repair vs. replacement $(n=1)$, studies with overlapping data $(n=45)$, irrelevant studies $(n=288)$, studies not in English $(n=5)$, studies discussing other forms of valve surgery $(n=4)$, studies of the same research $(n=2)$, or studies without control groups $(n=19)$. Ultimately, 31 studies were identified, in which 5 studies met the criteria stated above. A total of 1365 patients were included (replacement/repair= 475/890). Additionally, regarding operation interventions, 660 of the studies involved ALMT and 705 involved MS (Fig. 1).

\subsection{Operative time}

Consistent evidence demonstrated that $\mathrm{CPB}$ time (1365 patients; WMD, 43.07 min longer, 95\% confidence interval (CI): $17.42-68.73 \mathrm{~min} ; P=0.001)$ and ACCT (1365 patients; WMD, 24.14 min longer; 95\% CI: $-0.13-48.41 \mathrm{~min} ; P=0.05$ ) were longer with ALMT when compared with MS, suggesting that ALMT was more technically demanding and timeconsuming (Fig. 2).

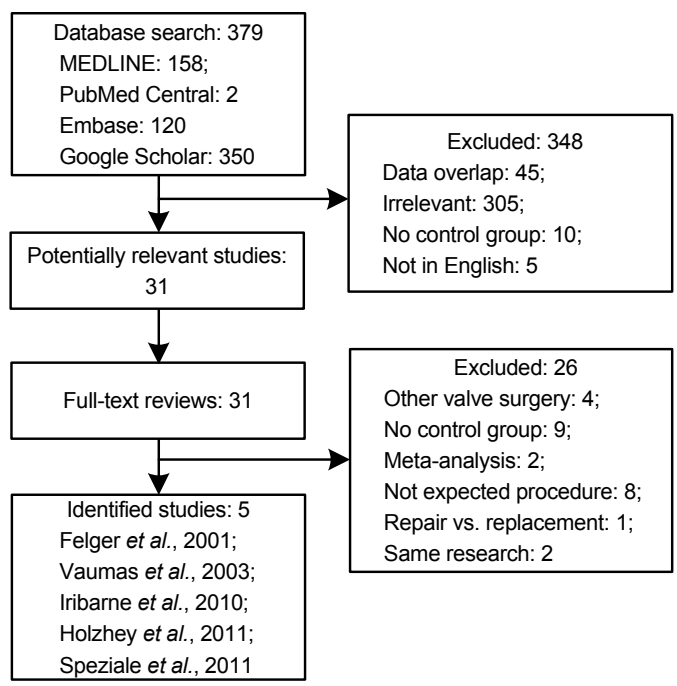

Fig. 1 Flow diagram of inclusion and exclusion criteria This flow diagram illustrates the databases searched in this review, the resulting number of potential studies subject to our inclusion criteria, and the number and reasons for excluding studies based on our exclusion criteria

Table 1 Characteristics of the five studies identified

\begin{tabular}{|c|c|c|c|c|c|c|c|c|c|c|}
\hline \multirow[t]{2}{*}{ Study } & \multirow[t]{2}{*}{ Period } & \multicolumn{2}{|c|}{$\begin{array}{l}\text { No. of } \\
\text { patients }\end{array}$} & \multicolumn{2}{|c|}{$\begin{array}{c}\text { Mean age } \\
\text { (year) }\end{array}$} & \multicolumn{2}{|c|}{ Male/female } & \multicolumn{2}{|c|}{ Replacement/repair } & \multirow[t]{2}{*}{ Design } \\
\hline & & ALMT & $\overline{\mathrm{MS}}$ & $\overline{\mathrm{ALMT}}$ & MS & ALMT & MS & ALMT & MS & \\
\hline $\begin{array}{l}\text { Felger et al. } \\
\quad(2001)\end{array}$ & $\begin{array}{l}\text { Sept. } 1996 \text { to } \\
\text { Nov. } 2000\end{array}$ & 55 & 100 & 59 & 62 & $27 / 28$ & $48 / 52$ & $21 / 34$ & $46 / 54$ & Case-control \\
\hline $\begin{array}{l}\text { de Vaumas } \\
\text { et al. }(2003)\end{array}$ & & 10 & 10 & & & & & $\begin{array}{l}\text { Repair } \\
\text { only }\end{array}$ & $\begin{array}{l}\text { Repair } \\
\text { only }\end{array}$ & Case-control \\
\hline $\begin{array}{l}\text { Iribarne et al. } \\
\quad \text { (2010) }\end{array}$ & $\begin{array}{l}\text { Jan. } 2000 \text { to } \\
\text { Dec. } 2008\end{array}$ & 382 & 382 & 59.1 & 60.7 & $184 / 198$ & $177 / 205$ & $95 / 287$ & $187 / 195$ & Case-control \\
\hline $\begin{array}{c}\text { Holzhey } \\
\text { et al. (2011) }\end{array}$ & $\begin{array}{l}\text { Aug. } 1999 \text { to } \\
\text { July } 2009\end{array}$ & 143 & 143 & 76 & 76 & $102 / 41$ & $98 / 45$ & $67 / 76$ & $59 / 84$ & Case-control \\
\hline $\begin{array}{c}\text { Speziale } \\
\text { et al. }(2011)\end{array}$ & $\begin{array}{c}\text { From Jan. } \\
2006\end{array}$ & 70 & 70 & 53.2 & 54 & $41 / 29$ & $43 / 27$ & $\begin{array}{l}\text { Repair } \\
\text { only }\end{array}$ & $\begin{array}{l}\text { Repair } \\
\text { only }\end{array}$ & $\mathrm{RCT}$ \\
\hline
\end{tabular}

ALMT: anterolateral minithoracotomy; MS: median sternotomy; RCT: randomized controlled trial 


\section{Cardiopulmonary bypass}

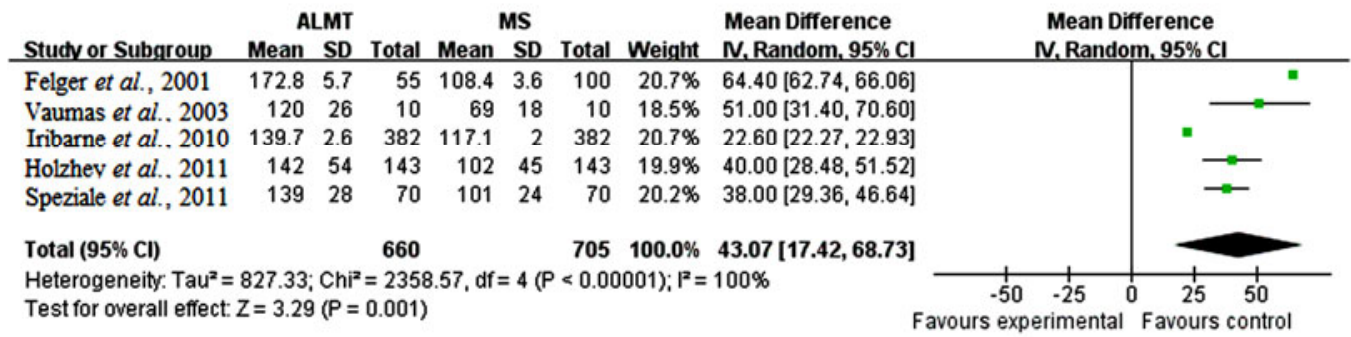

\section{Aortic cross-clamp time}

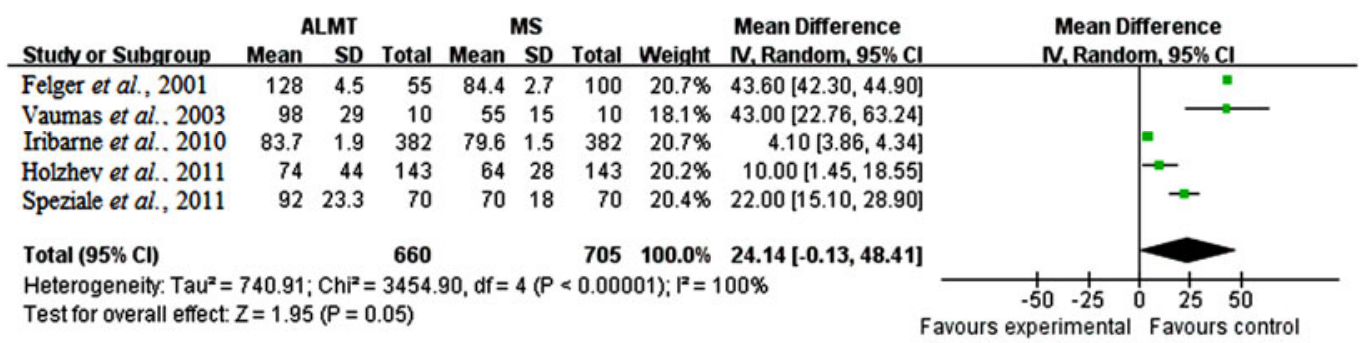

Fig. 2 Operative time of ALMT and MS in the five identified studies

Cardiopulmonary bypass (CPB) time and aortic cross-clamp time (ACCT) were significantly longer in the ALMT group than in the MS group

\subsection{Peri-operative mortality}

Peri-operative mortality is one of the most important outcome measures for evaluating efficiency and safety, defined as death from all causes within 30 post-operative days. One study with mortality data was excluded (Felger et al., 2001) because the mitral valve surgery data were mixed with those from aortic valve surgery. Only one randomized trial by Speziale et al. (2011) showed no difference in operative mortality (2/70 in ALMT vs. 1/70 in MS; $P=0.99)$. Causes of death were stroke in one case, adult respiratory distress syndrome in one case, and post-operative low output in one case. Iribarne et al. (2010) showed no significant difference in peri-operative mortality $(1.8 \%$ vs. $1.8 \% ; P=0.622)$ or one-year mortality $(5.0 \%$ vs. $3.9 \% ; P=0.599)$ between the ALMT and MS groups. According to the results of the metaanalysis, three studies mentioned equivalent perioperative mortality between ALMT and MS (Iribarne et al., 2010; Holzhey et al., 2011; Speziale et al., 2011), demonstrating no significant difference between these two procedures (1190 patients; $\mathrm{OR}=1.18$, 95\% CI: 0.61-2.30; $P=0.62$ ) (Table 2; Fig. 3).

\subsection{Re-operation for bleeding}

One main advantage regarding ALMT relates to reduced blood loss and re-operation for bleeding. The largest study, by Iribarne et al. (2010), included 764 patients. The incidence of re-operation for bleeding in ALMT was found to be equivalent to that achieved with traditional sternotomy. Four studies met the inclusion criteria (Felger et al., 2001; Iribarne et al., 2010; Holzhey et al., 2011; Speziale et al., 2011) and showed no significant difference between ALMT and MS (OR=1.27, 95\% CI: 0.75-2.17; $P=0.37$ ) (Table 2; Fig. 3).

\subsection{Neurologic events}

Some researchers suggest that neurologic events may occur with greater frequency in patients undergoing the minimally invasive approach because of inadequate de-airing (Anyanwu and Adams, 2012). The main neurologic events included transient/ permanent stroke and ischemic attack. The morbidity of peri-operative neurologic events in the randomized trial by Speziale et al. (2011) was similar between ALMT and MS ( $1.4 \%$ vs. $2.8 \% ; P=0.99)$. Further, no 
Table 2 Meta-analysis of post-operative adverse events

\begin{tabular}{lcccccc}
\hline \multicolumn{1}{c}{ Outcome } & $\begin{array}{c}\text { No. of } \\
\text { patients }\end{array}$ & $\begin{array}{c}\text { No. of } \\
\text { studies }\end{array}$ & $\begin{array}{c}\text { OR/WMD } \\
(95 \% \mathrm{CI})\end{array}$ & $P$ & \multicolumn{2}{c}{ Heterogeneity } \\
\cline { 5 - 7 } & 1190 & 3 & $1.18(0.61-2.30)$ & 0.62 & 0.30 & 0.86 \\
\hline Peri-operative mortality & 1345 & 4 & $1.27(0.75-2.17)$ & 0.37 & 3.06 & 0.38 \\
Re-operation for bleeding & 1345 & 4 & $0.84(0.26-2.70)$ & 0.77 & 4.50 & 0.21 \\
Neurologic events & 1205 & 3 & $0.65(0.43-0.99)$ & 0.05 & 3.81 & 0.15 \\
Arrhythmias & 1345 & 4 & $1.17(0.27-5.07)$ & 0.84 & 1.29 & 0.73 \\
Myocardial infarction & 1205 & 3 & $1.07(0.40-2.87)$ & 0.89 & 2.56 & 0.28 \\
Gastrointestinal complications & 1345 & 4 & $0.88(0.48-1.60)$ & 0.67 & 0.59 & 0.9 \\
Renal insufficiency & & & & & &
\end{tabular}

OR: odds ratio; WMD: weighted mean difference

significant difference was found in four eligible studies $(\mathrm{OR}=0.84,95 \% \mathrm{CI}: 0.26-2.70 ; P=0.77)$ (Felger et al., 2001; Iribarne et al., 2010; Holzhey et al., 2011; Speziale et al., 2011) (Table 2; Fig. 3).

\subsection{Arrhythmias and myocardial infarction}

It is known that the less traumatic the cardiac procedure, the less potent the provoked peri-operative arrhythmias. Most peri-operative arrhythmias involve atrial fibrillation. Three studies in our meta-analysis found that 580 ALMT patients had less atrial fibrillation than $625 \mathrm{MS}$ patients $(\mathrm{OR}=0.65,95 \% \mathrm{CI}$ : 0.43-0.99; $P=0.05$ ) (Felger et al., 2001; Iribarne et al., 2010; Holzhey et al., 2011) (Table 2; Fig. 3). The study by Asher et al. (1999), which was excluded for lack of a definition regarding the style of incision, showed a trend of low morbidity for atrial fibrillation in minimally invasive procedures compared with conventional sternotomy ( $28.6 \%$ vs. $40.0 \% ; P=0.20)$.

It is known that peri-operative myocardial infarction can be induced by intra-operative coronary artery injury and thrombosis. Four studies have discussed this question (Felger et al., 2001; Iribarne et al., 2010; Holzhey et al., 2011; Speziale et al., 2011). However, no difference was found between ALMT and MS regarding peri-operative myocardial infarction $(\mathrm{OR}=1.17,95 \% \mathrm{CI}$ : $0.27-5.07 ; P=0.84)$ (Table 2; Fig. 3).

\subsection{Gastrointestinal complications}

Gastrointestinal complications always refer to stress ulcer and bleeding. Three studies with 1205 patients revealed no significant difference between ALMT and MS (OR=1.07, 95\% CI: 0.40-2.87; $P=0.89$ ) (Felger et al., 2001; Iribarne et al., 2010; Holzhey et al., 2011) (Table 2; Fig. 3).

\subsection{Renal insufficiency}

Post-operative renal insufficiency is defined as an increase in the serum creatinine level greater than $2 \mathrm{mg} / \mathrm{dl}$. The largest study, by Iribarne et al. (2010), showed that peri-operative renal failure was similar between ALMT and MS [7/382 (1.8\%) vs. 5/382 (1.3\%); $P=0.773$. The RCT by Speziale et al. (2011) revealed the same result $[3 / 70(4.3 \%)$ vs. $3 / 70(4.3 \%)]$. Four studies that met the inclusion criteria (Felger et al., 2001; Iribarne et al., 2010; Holzhey et al., 2011; Speziale et al., 2011) showed no difference between ALMT and MS (OR=0.88, 95\% CI: 0.48-1.60; $P=0.67$ ) (Table 2; Fig. 3).

\subsection{Length of hospital stay, post-operative pain, and costs}

Does a more rapid recovery translate into a shorter stay in the hospital and, therefore, reduced costs? LOHS is a measure of patient recovery following surgery. The LOHSs of the ALMT group in three studies were significantly shorter than those in the MS group (WMD, $2.95 \mathrm{~d}$ shorter, 95\% CI: -3.45$-2.44 \mathrm{~d} ; P<0.00001$ ) (Fig. 3) (Felger et al., 2001; Holzhey et al., 2011; Speziale et al., 2011). However, additional multi-center studies should be performed in the future to compare recovery rates between ALMT and MS.

Less post-operative pain and a faster return to normal activity in ALMT are the most obvious advantages over MS. All three studies that measured post-operative pain levels reported less pain in ALMT compared with MS (Walther et al., 1999; Felger et al., 2001; Speziale et al., 2011). Speziale et al. (2011), the only randomized trial in our study, reported pain scores during the first $6 \mathrm{~d}$ after the operation. 
Length of hospital stay

\begin{tabular}{|c|c|c|c|c|c|c|c|c|c|}
\hline Study or Subgroup & $\begin{array}{l}\text { AL } \\
\text { Mean }\end{array}$ & LMT & Total & Mean & US & Total & Weight & $\begin{array}{l}\text { Mean Difference } \\
\text { N. Random, } 95 \% \mathrm{Cl}\end{array}$ & $\begin{array}{l}\text { Mean Difference } \\
\text { N. Random, } 95 \% \mathrm{Cl}\end{array}$ \\
\hline Felger et al., 2001 & 4.9 & 0.6 & 55 & 7.9 & 0.6 & 100 & $87.7 \%$ & $-3.00[-3.20,-2.80]$ & \\
\hline Holzhev et al. 2011 & 17 & 13 & 143 & 18 & 9.5 & 143 & $3.6 \%$ & $-1.00[-3.64,1.64]$ & \\
\hline Speziale et al., 2011 & 8.6 & 4.7 & 70 & 11.8 & 5.2 & 70 & $8.7 \%$ & $-3.20[-4.84,-1.56]$ & \\
\hline Total $(95 \% \mathrm{Cl})$ & & & 268 & & & 313 & $100.0 \%$ & $-2.95[-3.45,-2.44]$ & \\
\hline \multicolumn{10}{|c|}{ 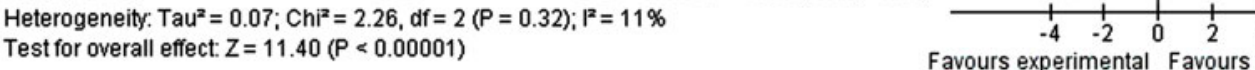 } \\
\hline
\end{tabular}

Peri-operative mortality

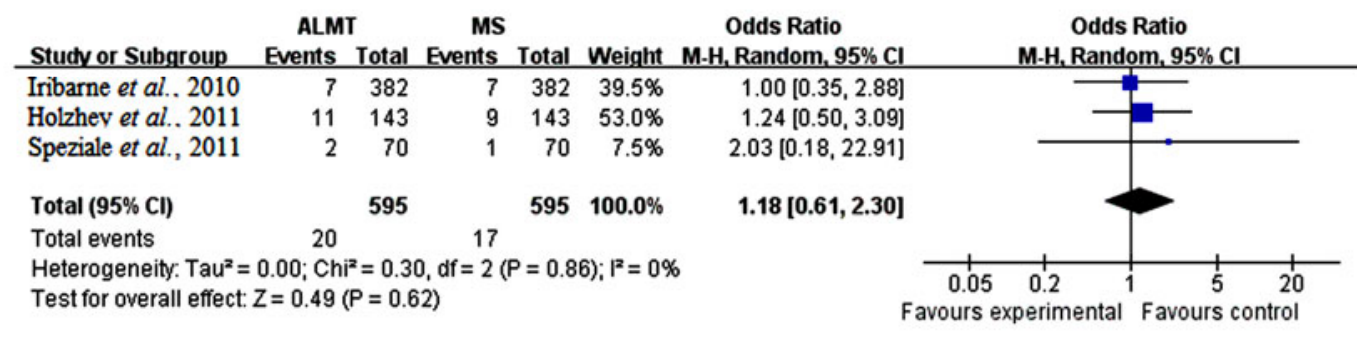

\section{Re-operation for bleeding}

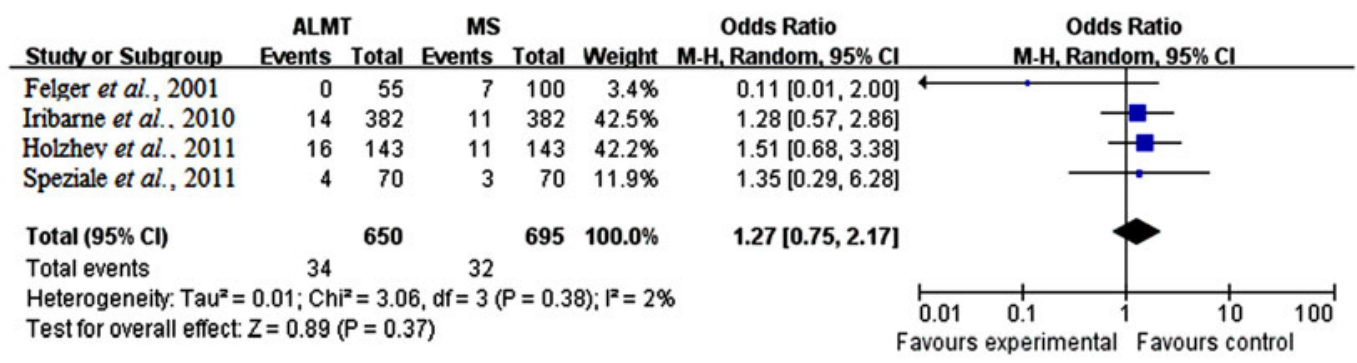

Neurological events

ALMT MS

Odds Ratio

Odds Ratio

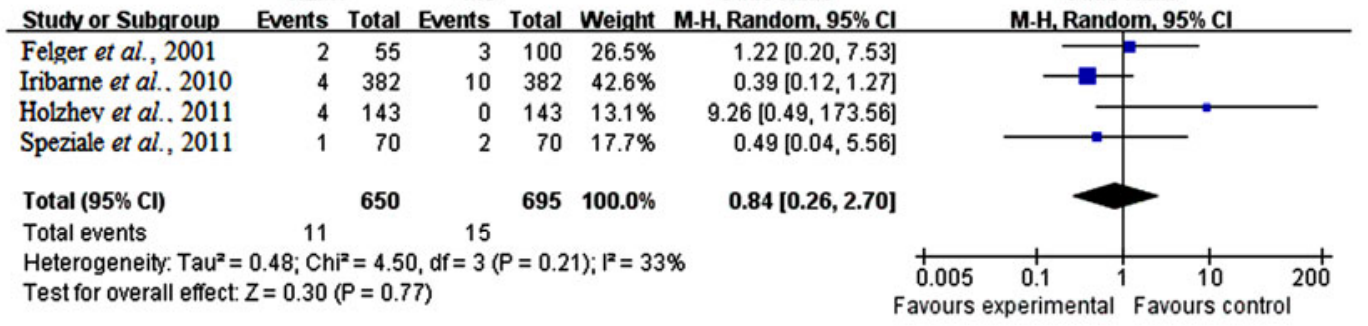

Arrhythmias

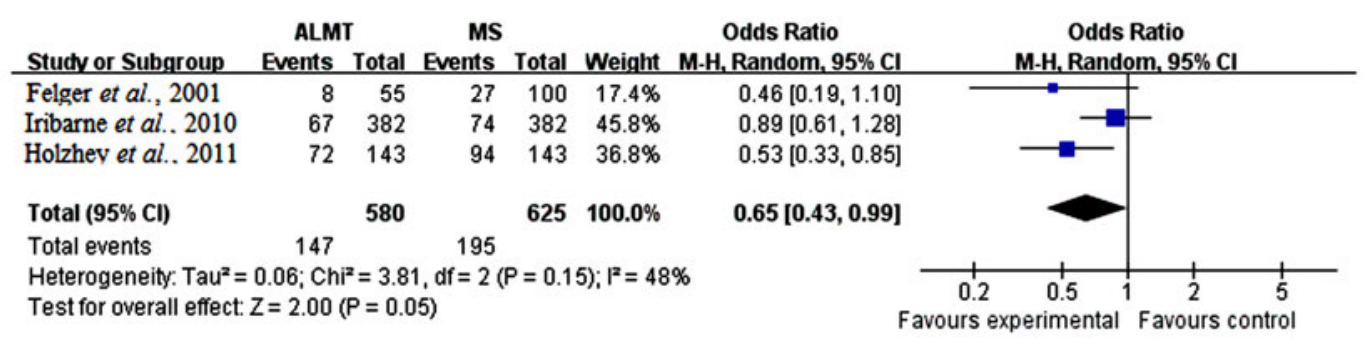

Fig. 3 To be continued 
Myocardial infarction

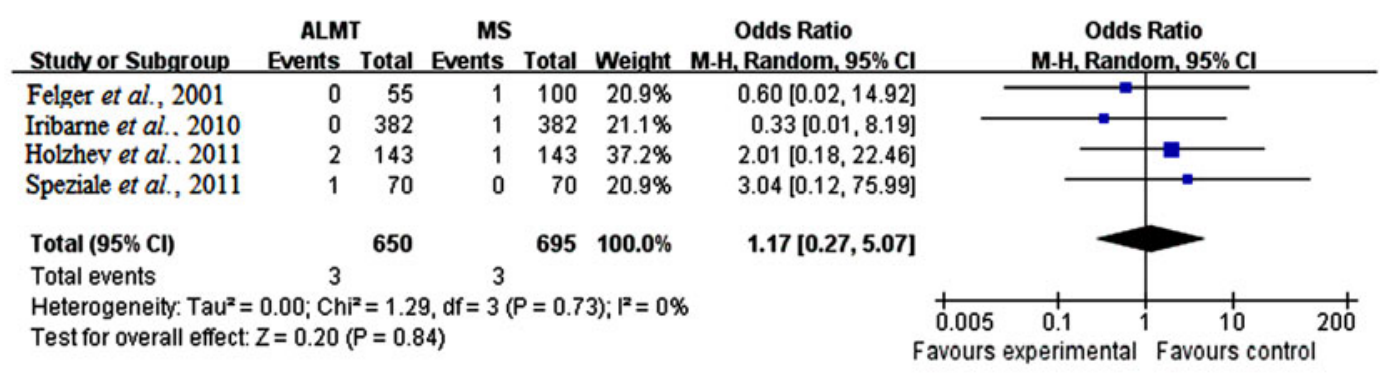

\section{Gastrointestinal complications}

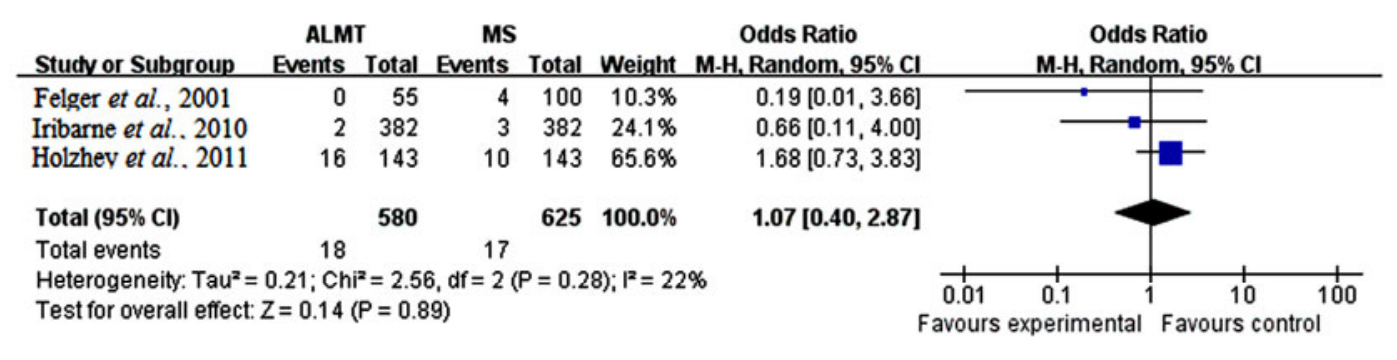

\section{Renal insufficiency}

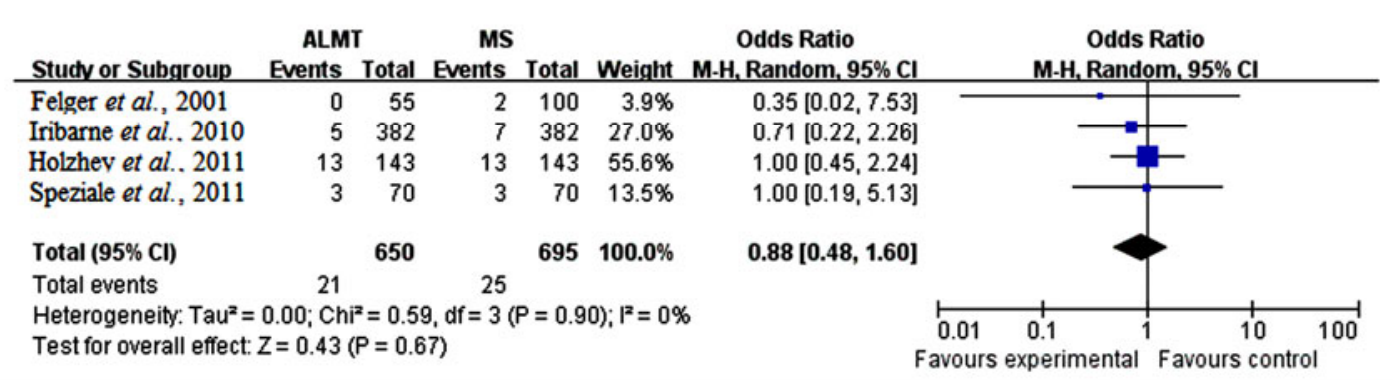

Fig. 3 Overall meta-analysis of outcome measures

The figure illustrates significant differences in arrhythmia and length of hospital stay, but no significant difference in other outcome measures

The mean pain scores were significantly lower in the ALMT group at all time points (the 2nd, 4th, and 6th post-operative days). In Felger et al. (2001), 11 re-operative patients who had a prior sternotomy for cardiac surgery reported less pain from ALMT and returned to regular activity more rapidly. Walther et al. (1999) revealed that patients undergoing ALMT had lower pain levels from the 3rd post-operative day onward.

Three studies recorded the reduced costs of the ALMT group compared with the MS group. Chitwood et al. (1997), Iribarne et al. (2012), and Cosgrove et al. (1998) equated this to $\$ 9165$ (34\%), $\$ 6721$, and $\$ 420(7 \%)$ in cost savings, respectively. Furthermore, discharge to the home, routinely or with a health aide, and satisfactory rehabilitation were more commonly reported in ALMT compared with MS, which can greatly save healthcare costs (Iribarne et al., 2012).

\subsection{Long-term results}

Long-term results included long-term survival and freedom from mitral valve events. Freedom from mitral valve events involved moderate to severe post-operative mitral regurgitation and any mitral re-operation. Anyanwu and Adams (2012) criticized the higher incidence of residual regurgitation by performing minimally invasive procedures in mitral valve repair. However, the only $\mathrm{RCT}$, by Speziale et al. (2011), comparing 70 patients undergoing ALMT with 
Table 3 Studies reporting long-term results of minimally invasive mitral valve surgery

\begin{tabular}{|c|c|c|c|c|c|c|c|}
\hline \multirow[t]{2}{*}{ Study } & \multirow[t]{2}{*}{ Institution } & \multicolumn{2}{|c|}{$\begin{array}{c}\text { Long-term survival } \\
(\%)\end{array}$} & \multirow[t]{2}{*}{$P$} & \multicolumn{2}{|c|}{$\begin{array}{l}\text { Freedom from mitral valve events } \\
(\%)\end{array}$} & \multirow[t]{2}{*}{$P$} \\
\hline & & ALMT & MS & & ALMT & MS & \\
\hline Aybek et al. (2006) & Frankfurt & 90.7 (at 6.3 years) & & & 96.2 (at 6.3 years) & & \\
\hline Martin et al. (2006) & Durham & $83 \pm 2$ (at 5 years) & & & $96 \pm 1$ (at 5 years) & & \\
\hline Seeburger et al. (2008) & Leipzig & 82.6 (at 5 years) & & & 96.3 (at 5 years) & & \\
\hline Iribarne et al. (2010) & New York & 91.9 (at 4 years) & 91.9 (at 4 years) & 0.569 & & & \\
\hline Holzhey et al. (2011) & Leipzig & $66 \pm 5.6$ (at 5 years) & $56 \pm 5.5$ (at 5 years) & 0.43 & & & \\
\hline Speziale et al. (2011) & Bari & 67 (at 2 years) & 69 (at 2 years) & 0.86 & 66 (at 2 years) & 67 (at 2 years) & 0.74 \\
\hline Reser et al. (2012) & Zürich & 100 (at 1.8 years) & & & 97.8 (at 1.8 years) & & \\
\hline
\end{tabular}

70 patients undergoing MS showed no significant difference in long-term survival $(P=0.86)$ and freedom from mitral valve events $(P=0.74)$. Other studies showed the same results as the RCT. The long-term survival ranged from $(66.0 \pm 5.6) \%$ to $100 \%$, and the freedom from mitral valve surgery ranged from $66.0 \%$ to $97.8 \%$ (Table 3). According to our research, ALMT would not increase the incidence of post-operative mitral residual regurgitation and mitral re-operation.

\section{Discussion}

In our study, we found that the potential benefits of ALMT, such as reduced incision size, can outweigh the potential drawbacks of limited operative exposure, longer CPB time and ACCT. Additionally, these potential benefits manifested as a more rapid recovery, which can translate into a shorter hospital stay and, therefore, reduced costs. Short- and longterm mortality rates were evaluated in our study. No significant difference was found between ALMT and MS in either peri-operative mortality or long-term survival. Conversely, the incidence of post-operative complications was similar between the ALMT and MS groups, except for fewer arrhythmias. All of the reviewed evidence demonstrated that ALMT is associated with equal mortality and incidence of postoperative adverse events.

Previously, endo-aortic balloon occlusion (EABO) was sometimes used in ALMT. However, surgeons increasingly discovered that EABO would increase the risk of aortic dissection and neurologic complications after operation compared with transthoracic clamping. Moreover, EABO was more expensive, more technically demanding, and less stable than transthoracic clamping. Thus, EABO has largely been replaced by transthoracic clamping (Aybek et al., 2000; Onnasch et al., 2002a; Reichenspurner et al., 2005).

"One-lung ventilation" was performed by twolumen endotracheal intubation to fully expose the surgical field. Some studies have indicated that potential lung injury may be induced by one-lung hyperventilation, pulmonary stretch, and pleural damage (de Abreu et al., 2003; Gothard, 2006; Unzueta et al., 2007). However, according to our research, a more rapid recovery can be observed in the ALMT group compared with the MS group. Two studies (Felger et al., 2001; Holzhey et al., 2011) have demonstrated the incidence of post-operative respiratory complications between ALMT and MS. Holzhey et al. (2011) showed no significant difference in the incidence of post-operative respiratory failure between ALMT and MS $(P>0.99)$. Felger et al. (2001) showed that the MS group was more likely to have prolonged ventilation ( $13 \%$ vs. $2 \%)$ and pneumonia ( $2 \%$ vs. $0 \%$ ) compared with the ALMT group. Thus, there is no strong evidence that ALMT can induce more severe lung injury than MS.

ALMT has been used more extensively worldwide in place of conventional sternotomy for the treatment of mitral valve disease, particularly in females to improve cosmetic results. The incisions range from 4 to $8 \mathrm{~cm}$ and can be hidden in the submammary groove, while those of conventional MS are much longer and more unsightly. Murtuza et al. (2008) found that 282 of 308 patients (91.5\%) were satisfied with the cosmetic result of ALMT. Three studies found that ALMT resulted in less pain and a higher quality of life in patients with mitral valve disease after operation (Walther et al., 1999; Felger 
et al., 2001; Speziale et al., 2011). Moreover, ALMT can maintain the continuity and integrity of the bony thorax, thereby preventing pectus carinatum and sternal infection.

Five meta-analyses have already been performed on minimal invasive heart surgery. Modi et al. (2008) showed that MIMVS was a safe and durable alternative to MS and was associated with equal mortality and neurologic events, less morbidity in terms of reduced incidence for re-operation for bleeding, a trend towards shorter hospital stay, less pain, and faster return to pre-operative function levels compared with conventional sternotomy, despite longer CPB time and ACCT. Ding et al. (2012) evaluated ALMT in congenital heart disease and suggested that this had a longer CPB time and ACCT, but shorter intubation time, ICU time, and LOHS. The remaining three studies compared a minimally invasive procedure with conventional sternotomy for aortic valve replacement (Murtuza et al., 2008; Brown et al., 2009; Khoshbin et al., 2011) and included RCTs and non-randomized studies. They concluded that a mini-sternotomy can be performed safely for aortic valve replacement without an increased risk of death, major complications (Khoshbin et al., 2011), a reduction in ICU stay time (Brown et al., 2009), or clinical benefit (Aybek et al., 2000). Moreover, we excluded 12 studies because they had no control groups (Loulmet et al., 1998; Mishra et al., 1999; Riess et al., 2001; Grossi et al., 2002; Onnasch et al., 2002b; Aybek et al., 2006; Martin et al., 2006; Seeburger et al., 2008; 2009; Glaubera et al., 2009; Müller et al., 2011; Reser et al., 2012), which ranged from 22 to 1339 in sample size. However, these studies, with 3085 patients in total, summarized the long-term clinical experience of ALMT, which is useful for making clinical decisions and ensuring the safety of ALMT.

One striking benefit of ALMT is the lesser rate of post-operative atrial fibrillation compared with MS. The mechanism, however, is not very clear. Asher et al. (1999) has shown that post-operative atrial fibrillation is often initiated from the left atrium. ALMT involves opening of the right atrium, followed by incision and entry to the mitral valve through the fossa ovalis. However, with median sternotomy, more often a conventional left atriotomy is performed for direct entry to the mitral valve. As a result, ALMT may be a less traumatic approach and therefore a less potent trigger of post-operative atrial fibrillation. Mathew et al. (2004) showed that bicaval venous cannulation (most often performed for mitral valve surgery) may predispose toward recurrent atrial fibrillation as a consequence of greater surgical injury. ALMT can avoid bicaval venous cannulation by using femoral cannulation instead.

Most selected studies included both high-risk and low-risk patients which were difficult to distinguish. Holzhey et al. (2011) had suggested that the outcome parameters are balanced between the groups of high-risk patients except for the strikingly reduced rate of post-operative atrial fibrillation in the ALMT group.

The present meta-analysis possesses limitations, such as the lack of large, multi-center prospective RCTs, concurrent tricuspid or septal defect repair, or atrial fibrillation ablation, and the different etiologies of mitral disease. Only one small RCT was identified. Thus, most of the studies were case-control studies. Random-effects models were applied because of variable outcome measures among studies and variable surgical data due to different selection criteria and patient characteristics among the different centers. As a result, the risk of bias was not assessed in the present meta-analysis. Hypothermic circulatory arrest time is a very important operative parameter for comparing ALMT with MS. However, all selected studies lacked these data. Some studies did not discuss the male to female ratio and the repair to replacement ratio, both of which can compromise the force of our research. Similarly, some patients in two of the selected reports (Iribarne et al., 2010; Holzhey et al., 2011) in our study did undertake not only isolated mitral valve repair, but also concurrent tricuspid or septal defect repair or atrial fibrillation ablation. Our study focussed on the type of the incision used in mitral surgery as the main criterion, rather than on etiology of mitral disease. Consequently, the study may result in an analysis of outcomes in a heterogeneous patient population with an unknown mix of ischemic, myxomatous, endocarditic, and rheumatic etiologies. Since the etiology of mitral valve disease is another important determinant of outcomes, this needs to be taken into account in the conclusions of this study. However, because all the studies lacked these data, it is difficult for us to require an analysis limited to a single pathology. 


\section{Conclusions}

ALMT is a more complex surgical procedure with longer CPB time and ACCT than MS. However, ALMT can offer patients with mitral valve disease more benefits by a trend towards longer survival, shorter LOHS, and less post-operative arrhythmia than MS. The incidence of other peri-operative complications of ALMT is equivalent to that of MS.

\section{Compliance with ethics guidelines}

Chao DING, Da-ming JIANG, Kai-yu TAO, Qun-jun DUAN, Jie LI, Min-jian KONG, Zhong-hua SHEN, and Ai-qiang DONG declare that they have no conflict of interest.

This article does not contain any studies with human or animal subjects performed by any of the authors.

\section{References}

Anyanwu, A.C., Adams, D.H., 2012. Should complex mitral valve repair be routinely performed using a minimally invasive approach? Curr. Opin. Cardiol., 27(2):118-124. [doi:10.1097/HCO.0b013e328350214f]

Asher, C.R., DiMengo, J.M., Arheart, K.L., et al., 1999. Atrial fibrillation early postoperatively following minimally invasive cardiac valvular surgery. Am. J. Cardiol., 84(6): 744-747.

Aybek, T., Dogan, S., Wimmer-Greinecker, G., et al., 2000. The micro-mitral operation comparing the port-access technique and the transthoracic clamp technique. J. Card. Surg., 15(1):76-81. [doi:10.1111/j.1540-8191.2000.tb00 446.x]

Aybek, T., Dogan, S., Risteski, P.S., et al., 2006. Two hundred forty minimally invasive mitral operations through right minithoracotomy. Ann. Thorac. Surg., 81(5):1618-1624. [doi:10.1016/j.athoracsur.2005.12.006]

Brown, M.L., McKellar, S.H., Sundt, T.M., et al., 2009. Ministernotomy versus conventional sternotomy for aortic valve replacement: a systematic review and meta-analysis. J. Thorac. Cardiovasc. Surg., 137(3):670-679. [doi:10. 1016/j.jtcvs.2008.08.010]

Byrne, J.G., Hsin, M.K., Adams, D.H., et al., 2000. Minimally invasive direct access heart valve surgery. J. Card. Surg., 15(1):21-34. [doi:10.1111/j.1540-8191.2000.tb00441.x]

Chitwood, W.R.Jr., Wixon, C.L., Elbeery, J.R., et al., 1997. Video-assisted minimally invasive mitral valve surgery. $J$ Thorac. Cardiovasc. Surg., 114(5):773-782. [doi:10. 1016/S0022-5223(97)70081-3]

Cosgrove III, D.M., Sabik, J.F., Navia, J.L., 1998. Minimally invasive valve operations. Ann. Thorac. Surg., 65(6): 1535-1539. [doi:10.1016/S0003-4975(98)00300-2]

de Abreu, M.G., Heintz, M., Heller, A., et al., 2003. One-lung ventilation with high tidal volumes and zero positive end-expiratory pressure is injurious in the isolated rabbit lung model. Anesth. Analg., 96(1):220-228. [doi:10.1213/ 00000539-200301000-00045]

de Vaumas, C., Philip, I., Daccache, G., et al., 2003. Comparison of minithoracotomy and conventional sternotomy approaches for valve surgery. J. Cardiothorac. Vasc.
Anesth., 17(3):325-328. [doi:10.1016/S1053-0770(03) 00051-X]

Ding, C., Wang, C., Dong, A., et al., 2012. Anterolateral minithoracotomy versus median sternotomy for the treatment of congenital heart defects: a meta-analysis and systematic review. J. Cardiothorac. Surg., 7:43. [doi:10. 1186/1749-8090-7-43]

Felger, J.E., Chitwood, W.R.Jr., Nifong, L.W., et al., 2001. Evolution of mitral valve surgery: toward a totally endoscopic approach. Ann. Thorac. Surg., 72(4):1203-1209. [doi:10.1016/S0003-4975(01)02978-2]

Gillinov, A.M., Mihaljevic, T., 2012. The future of mitral valve surgery. Tex. Heart. Inst. J., 39(6):840-841.

Gillinov, A.M., Banbury, M.K., Cosgrove, D.M., 2000. Hemisternotomy approach for aortic and mitral valve surgery. J. Card. Surg., 15(1):15-20. [doi:10.1111/j.15408191.2000.tb00440.x]

Glaubera, M., Karimova, J.H., Farneti, P.A., et al., 2009. Minimally invasive mitral valve surgery via right minithoracotomy. Multimedia Manual Cardiothorac. Surg., 2009(0122):mmcts.2008.003350. [doi:10.1510/mmcts. 2008.003350]

Glower, D.D., Siegel, L.C., Galloway, A.C., et al., 2001. Predictors of operative time in multicenter port-access valve registry: institutional differences in learning. Heart Surg. Forum, 4(1):40-46.

Gothard, J., 2006. Lung injury after thoracic surgery and one-lung ventilation. Curr. Opin. Anaesthesiol., 19(1): 5-10. [doi:10.1097/01.aco.0000192783.40021.c1]

Grossi, E.A., Galloway, A.C., LaPietra, A., et al., 2002. Minimally invasive mitral valve surgery: a 6-year experience with 714 patients. Ann. Thorac. Surg., 74(3):660-664. [doi:10.1016/S0003-4975(02)03754-2]

Gundry, S.R., Shattuck, O.H., Razzouk, A.J., et al., 1998. Facile minimally invasive cardiac surgery via ministernotomy. Ann. Thorac. Surg., 65(4):1100-1104. [doi:10. 1016/S0003-4975(98)00064-2]

Holzhey, D.M., Shi, W., Borger, M.A., et al., 2011. Minimally invasive versus sternotomy approach for mitral valve surgery in patients greater than 70 years old: a propensitymatched comparison. Ann. Thorac. Surg., 91(2):401-405. [doi:10.1016/j.athoracsur.2010.08.006]

Iribarne, A., Russo, M.J., Easterwood, R., et al., 2010. Minimally invasive versus sternotomy approach for mitral valve surgery: a propensity analysis. Ann. Thorac. Surg., 90(5):1471-1478. [doi:10.1016/j.athoracsur.2010.06.034]

Iribarne, A., Easterwood, R., Russo, M.J., et al., 2012. Comparative effectiveness of minimally invasive versus traditional sternotomy mitral valve surgery in elderly patients. J. Thorac. Cardiovasc. Surg., 143(4):S86-S90. [doi:10.1016/j.jtcvs.2011.10.090]

Khoshbin, E., Prayaga, S., Kinsella, J., et al., 2011. Ministernotomy for aortic valve replacement reduces the length of stay in the cardiac intensive care unit: metaanalysis of randomized controlled trials. BMJ Open, 1(2):e000266. [doi:10.1136/bmjopen-2011-000266]

Loulmet, D.F., Carpentier, A., Cho, P.W., et al., 1998. Less invasive techniques for mitral valve surgery. J. Thorac. Cardiovasc. Surg., 115(4):772-779. [doi:10.1016/S00225223(98)70354-X]

Martin, J.S., Davis, R.D., Glower, D.D., 2006. Intermediateterm results of 505 consecutive minithoracotomy mitral 
valve procedures. Innovat. Technol. Tech. Cardiothorac. Vasc. Surg., 1(3):99-104.

Mathew, J.P., Fontes, M.L., Tudor, I.C., et al., 2004. A multicenter risk index for atrial fibrillation after cardiac surgery. JAMA, 291(14):1720-1729. [doi:10.1001/jama.291. 14.1720]

Mishra, Y.K., Malhotra, R., Mehta, Y., et al., 1999. Minimally invasive mitral valve surgery through right anterolateral minithoracotomy. Ann. Thorac. Surg., 68(4):1520-1524. [doi:10.1016/S0003-4975(99)00963-7]

Modi, P., Hassan, A., Chitwood, W.R., 2008. Minimally invasive mitral valve surgery: a systematic review and meta-analysis. Eur. J. Cardiothorac. Surg., 34(5):943952. [doi:10.1016/j.ejcts.2008.07.057]

Mohr, F.W., Falk, V., Diegeler, A., et al., 1998. Minimally invasive port-access mitral valve surgery. J. Thorac. Cardiovasc. Surg., 115(3):567-576. [doi:10.1016/S00225223(98)70320-4]

Murtuza, B., Pepper, J.R., Stanbridge, R.D., et al., 2008. Minimal access aortic valve replacement: is it worth it? Ann. Thorac. Surg., 85(3):1121-1131. [doi:10.1016/j. athoracsur.2007.09.038]

Müller, L.C., Hangler, H., Kilo, J., et al., 2011. Minimally invasive mitral valve surgery in the old patient. Eur. Surg., 43(2):96-98. [doi:10.1007/s10353-011-0601-2]

Onnasch, J.F., Schneider, F., Falk, V., et al., 2002a. Five years of less invasive mitral valve surgery: from experimental to routine approach. Heart. Surg. Forum, 5(2):132-135.

Onnasch, J.F., Schneider, F., Falk, V., et al., 2002b. Minimally invasive approach for redo mitral valve surgery: a true benefit for the patient. J. Card. Surg., 17(1):14-19. [doi: 10.1111/j.1540-8191.2001.tb01214.x]

Reichenspurner, H., Detter, C., Deuse, T., et al., 2005. Video and robotic-assisted minimally invasive mitral valve surgery: a comparison of the port-access andtransthoracic clamp techniques. Ann. Thorac. Surg., 79(2):485-490. [doi:10.1016/j.athoracsur.2004.06.120]

Reser, D., Jacobs, S., Grünenfelder, J., et al., 2012. Outcomes of minimally invasive mitral valve surgery through a right lateral mini-thoracotomy. Thorac. Cardiovasc. Surg., 60(S01):V205. [doi:10.1055/s-0031-1297595]
Riess, F.C., Moshar, S., Bader, R., et al., 2001. Correction of congenital heart defects and mitral valve operations using limited anterolateral thoracotomy. Heart. Surg. Forum, 4(1):34-39.

Seeburger, J., Borger, M.A., Falk, V., et al., 2008. Minimal invasive mitral valve repair for mitral regurgitation: results of 1339 consecutive patients. Eur. J. Cardiothorac. Surg., 34(4):760-765. [doi:10.1016/j.ejcts.2008.05.015]

Seeburger, J., Borger, M.A., Falk, V., et al., 2009. Minimally invasive mitral valve surgery after previous sternotomy: experience in 181 patients. Ann. Thorac. Surg., 87(3): 709-714. [doi:10.1016/j.athoracsur.2008.11.053]

Soltesz, E.G., Cohn, L.H., 2007. Minimally invasive valve surgery. Cardiol. Rev., 15(3):109-115. [doi:10.1097/01. crd.0000233769.92470.75]

Speziale, G., Nasso, G., Esposito, G., et al., 2011. Results of mitral valve repair for Barlow disease (bileaflet prolapse) via right minithoracotomy versus conventional median sternotomy: a randomized trial. J. Thorac. Cardiovasc. Surg., 142(1):77-83. [doi:10.1016/j.jtcvs.2010.08.033]

Sündermann, S.H., Scherman, J., Falk, V., 2012. Minimally invasive and transcatheter techniques in high-risk cardiac surgery patients. Inter. Cardiol., 4(2):253-263. [doi:10. 2217/ica.12.15]

Unzueta, M.C., Casas, J.I., Moral, M.V., 2007. Pressurecontrolled versus volume-controlled ventilation during one-lung ventilation for thoracic surgery. Anesth. Analg., 104(5):1029-1033. [doi:10.1213/01.ane.0000260313. 63893.2f]

Vanermen, H., Wellens, F., de Geest, R., et al., 1999. Videoassisted port-access mitral valve surgery from debut to routine surgery. Will trocar-port-access cardiac surgery ultimately lead to robotic cardiac surgery? Semin. Thorac. Cardiovasc. Surg., 11(3):223-234.

Walther, T., Falk, V., Metza, S., et al., 1999. Pain and quality of life after minimally invasive versus conventional cardiac surgery. Ann. Thorac. Surg., 67(6):1643-1647. [doi: 10.1016/S0003-4975(99)00284-2]

\section{中文瀶要:}

本文题目: 二尖瓣瓣膜病行右前外侧小切口与胸骨正中切口手术研究的 meta 分析 Anterolateral minithoracotomy versus median sternotomy for mitral valve disease: a meta-analysis

研究目的: 二尖瓣瓣膜病越来越趋向于应用右前外侧小切口（ALMT）替代胸骨正中切口（MS）进行手术, 因为其更美观、微创。本文主要是比较分析 ALMT 组与 MS 组的手术参数及术后结果。

研究方法: 从 1996 年 1 月至 2013 年 1 月期间发表的英文论文中, 选出 1 篇随机对照研究及 4 篇病例对照 研究进行分析。

重要结论: 目前的临床数据显示, 相比较于传统的胸骨正中切口二尖瓣手术, 右前外侧小切口手术是一种 安全、有效的方法, 具有较好的近期和远期疗效。

关键词组：微创手术; 胸部小切口; 正中开胸; 二尖瓣; Meta 分析 